Integritas 3.1 (Spring 2014), pp. 1-21.

doi: 10.6017/integritas.v3i1p1

\title{
Genetic Determinism in the Post-Genomic Age
}

\begin{abstract}
Marc A.T. Muskavitch
There have been many forms of determinism over the ages, the most recent of which is based in the growing understanding of genetics. This essay questions the ways people today use this growing body of knowledge to make health care decisions, or decisions about reproduction. It goes on to explore epigenetics, the science of environmental factors influencing genes, and questions whether grace, understood as a theological category, might influence a person's biological destiny.
\end{abstract}

The search for certainty in an uncertain world has engendered varied strains of determinism through history. As our understanding of genetics and genomics has grown, genetic determinism has taken hold among some scientists, physicians, and members of the general public_-positing that genes we inherit from our forebears determine our biological destinies. Genes we inherit (i.e., our "genotypes") and changes that occur in them as we live can affect our lives dramatically. Genotypes that predispose us toward cancer, metabolic disease, and degenerative decline can create challenges and motivate profound choices in our lives. Yet, as we have grown in our understanding of the relationships between our genotypes and our biology, we have learned that genetic predispositions toward disease are not the sole determinants of our biological destinies. This essay will discuss how the impacts of genotypes that predispose us toward disease can be modulated by other genes we inherit, and by the interactions of our genotypes with our environments. We will explore, as well, whether those impacts may be affected by the power of mind-body interactions and the power of grace in our lives.

Marc A.T. Muskavitch is a professor of biology at Boston College. He is a widely published geneticist and co-inventor with more than a dozen patents. His research interests include malaria and vector biology, vector mosquito genomics and genetics, and malaria parasite proteasome function. His work has appeared in numerous scientific journals, including Acta Tropica, Genetics, Cell, Nature, and Science. 


\section{The Rise of Genetic Determinism}

One hallmark of humanity is our desire to know the future. Since the dawn of humanity, we have revered and feared those who claim to be able to predict the future. We have striven to divine the factors and forces that shape our futures. Across many millennia, varied individuals and groups have crafted frameworks they hope or believe can predict their own futures and the futures of others. Such deterministic frameworks hold that particular outcomes are the necessary consequences of pre-existing states or conditions. Various schools of thought have defined different deterministic frameworks they contend can define future outcomes for themselves and for others.

The history of thought offers many deterministic frameworks that have influenced the lives of individuals and the courses of nations. These frameworks reinforce the belief that individuals can predict certain facets of our futures, and enable those who so choose to define "us" and "them," the saved and the damned, the well and the unwell. For centuries, the Calvinist branch of Protestantism, which espouses a form of theological determinism, has held that "unconditional election" reflects the choice by God of those souls that will be saved and those that will not, based not on the merits of individuals, but on His will alone. In this case, it is the will of an omnipotent God that determines whether each soul is saved or damned. Cultural determinism has held that the culture within which we develop determines our personalities, inclinations, choices and actions. In this case, the cultural environments within which we grow and live define our futures, for good or ill. The cultures that humans create through imagination, communication, and socialization determine who we become and how we choose to act. Other deterministic frameworks formulated over time have included biological, environmental, economic, social, technological, and geographic determinisms. As scientists have now defined the complete sequence of the human genome ${ }^{1}$ and have continued to develop techniques to map genes underlying predispositions toward human disease and wellness, ${ }^{2}$ we can now add genetic determinism to the roster of deterministic frameworks.

A seminal step toward formulation of the framework of genetic determinism was taken by August Weismann (I834-I9I4), a theorist who contended that inherited "determinants" in "germ plasm" — which we now define as "genes" encoded within "deoxyribonucleic acid (DNA)"-were acted upon by Darwinian selection. These determinants, and variation that arises in them through the process of mutation, were passed from generation to generation, defining the form and function of an organism as well as its competitiveness and reproductive fitness. ${ }^{3}$

1 E.S. Lander et al., "Initial sequencing and analysis of the human genome," Nature 409:6822 (Feb 15 2001): 860-921. See also J.C. Venter et al., "The sequence of the human genome," Science 291:5507 (Feb 16 2001), 1304-51.

21000 Genomes Project Consortium, "A map of human genome variation from population-scale sequencing," Nature 467:7319 (Oct 28, 2010), 1061-73. See also P.M. Visscher, M.A. Brown, M.I. McCarthy, and J. Yang, "Five years of GWAS discovery," The American Journal of Human Genetics 90:1 (Jan 13 2012), 7-24.

3 A. Weissman, The Germ-Plasm: A Theory of Heredity, translated by W.N. Parker and H. Rönnfeldt (New 
Gregor Mendel's studies demonstrated that genes generally occur in pairs and that the two members of each pair are transmitted randomly between generations. Subsequent discoveries and rediscoveries during the twentieth century enabled refinement of the underpinnings of this genetic framework. ${ }^{4}$ Morgan and Sturtevant demonstrated that genes are found within chromosomes. Avery, MacLeod, and McCarty proved that DNA constitutes the genetic material in bacteria, and others extended this proof to fungi, plants, and animals. Watson and Crick defined the physical structure of DNA as an antiparallel double helix composed of pairs of DNA bases ("base pairs"). ${ }^{5}$ At the start of the twenty-first century, two consortia comprised of hundreds of scientists completed the sequence of the human genome, revealing that it is composed of nearly three billion base pairs of DNA. Subsequently, scientists have developed an extensive, expanding array of techniques that enable mapping of genetic variation within the human genome-the "blueprint" for the human organism - and the association of specific genetic variation with predispositions toward numerous conditions and diseases.

The creative industry of geneticists and genomicists has engendered the hope that genetic variation can predict whether we and those around us will be healthy or afflicted.

The ongoing accrual of genetic information and the association of specific genetic variation, or "genotypes," with specific conditions and diseases, or "phenotypes," have led to the invigoration and expansion of human genetics. The creative industry of geneticists and genomicists has, in turn, engendered the hope that genetic variation can predict whether we and those around us will be healthy or afflicted, will encounter health risks that should affect our lifestyles and behavioral choices, will benefit from some medicines and not from others, and will lead long and productive or short and difficult lives. This multifaceted effort has encouraged among many scientists, medical professionals, and members of the lay public a belief in a framework of genetic determinism that holds that our health and well-being are determined largely by the genes we inherit from our parents and the genetic variation that arises within us during the course of our lives. We will begin by exploring the extent to which this framework of genetic determinism is true, and the substantial extent to which it is not strictly true.

York: Charles Scribner's Sons, 1893).

4 S.J. Gould, The Structure of Evolutionary Theory (Cambridge: Belknap Press, 2002). See also C. Nüsslein-Volhard, Coming to Life: How Genes Drive Development (Carlsbad: Kales Press, 2006).

5 J.D. Watson and F.H. Crick, "Molecular structure of nucleic acids; a structure for deoxyribose nucleic acid," Nature 171:4356 (Apr 25, 1953), 737-8. 


\section{Genotypes and Biological Destiny}

Observations of the inheritance of many traits, including diseases, within human families formed the foundations of human genetics. ${ }^{6}$ This has led to the colloquial view that a family may have "good genes" or "bad genes." The former, if good fortune predominates within a family's history, and the latter, if misfortune predominates. Similarly, we sometimes say that the unfortunate few within an otherwise fortunate family must have picked up a "bad gene" along the way. The very real heritability of discernible traits, including some forms of disability and disease, have reinforced these notions over the centuries and provided fertile ground for growth of the notion of genetic determinism.

Generations of casual and systematic genetic analysis have led to the identification of thousands of "Mendelian" traits, or phenotypes. These are termed Mendelian traits because they segregate through familial pedigrees in manners reflective of their association with mutations, or genotypes, that affect genes located on one or more of the 24 human chromosomes, and because Mendel is credited with the initial description of the segregation of inherited genetic determinants. These thousands of traits include many well-known characteristics such as albinism, hemophilia, cystic fibrosis, and color blindness. More recently, the inheritance of genetic variation underlying various forms of cancer, neurological disorders, and other diseases, ${ }^{7}$ as well as the efficacies of different medicines, ${ }^{8}$ have been characterized more extensively.

As in other fields of specialization, geneticists have created a special lexicon to communicate the relationships between inherited genetic determinants and observed traits, which we will explore in brief.

Genotype is the set of genetic variants, or alleles, for a given gene carried by an individual. Humans are diploid organisms, with the prospect of carrying two copies of every or almost every gene, in females or males, respectively. Females carry two copies of the X chromosome and each of 22 "autosomes," for a total of 46 chromosomes. Males carry two copies of each autosome, one copy of the X chromosome, and one copy of the Y chromosome, again totaling 46 chromosomes. Thus, females carry two copies of every gene on the $\mathrm{X}$ chromosome and each autosome while males carry two copies of every autosomal gene, one copy of each $\mathrm{X}$ chromosome gene, and one copy of each $\mathrm{Y}$ chromosome gene. In this sense, we carry genetic "back-ups" for most of our genes. Reductions in gene function usually affect our health discernably only after both copies of a given gene are altered (with the exception of truly dominant traits, as outlined below). This generalization is consistent with the increased occurrence in males, as compared to females, of diseases linked to the $\mathrm{X}$ chromosome.

6 E. Thompson, "The structure of genetic linkage data: from LIPED to 1M SNPs," Human Heredity 71:2 (2011), 86-96.

7 P.M. Visscher, M.A. Brown, M.I. McCarthy, and J. Yang, "Five years of GWAS discovery," The American Journal of Human Genetics 90:1 (Jan 13 2012), 7-24.

8 M. Whirl-Carrillo, E.M. McDonagh, J.M. Hebert, L. Gong, K. Sangkuhl, C.F. Thorn, R.B. Altman, and T.E. Klein, "Pharmacogenomics knowledge for personalized medicine," Clinical Pharmacology \& Therapeutics 92:4 (2012), 414-417. 
Phenotype is an observable characteristic, or trait, that can be described, and in many instances quantified, as being more or less severe. The "normal" phenotype within a given population is also termed the "wild type" phenotype, as it is reflective of the predominant "natural" or "wild" phenotype in a given population.

Wild type genes, or wild type alleles (wild type variants), are versions of a gene that carry out the normal function of that gene.

Variant genes, or mutated alleles (mutated variants, or mutations), are versions of a gene that differ from the wild type allele. They may support a reduced level of gene function (partial loss-of-function allele) or may be incapable of providing any gene function (null allele), or they may encode a novel product that acquires "new" but deleterious properties (gain-of-function allele).

Furthermore, geneticists have come to understand that different traits exhibit differing modes of inheritance, which can be described as recessive, dominant, or pseudodominant.

Cystic fibrosis is a recessive trait. ${ }^{9}$ A child must inherit two mutated alleles of the CFTR gene (partial loss-of-function alleles, or null alleles)—one from each parent-in order to exhibit the disorder. In this case, the level of disease gene function is reduced in all cells in which the gene is normally active, resulting in occurrence of the disorder. Such traits often occur in alternating generations within an affected pedigree. In such instances, one wild type copy of the gene will prevent the disorder when present in combination with one mutated copy of the gene. So, this is termed a recessive trait.

Huntington's Disease is a dominant trait. ${ }^{10}$ An individual who inherits one mutated allele of the HTT gene (gain-of-function allele) and survives to a sufficient age will exhibit the disorder. In such cases, the presence of one copy of the disease-predisposing mutated allele will result in the disorder, even in the presence of a wild type allele. Such traits often occur within every generation of an affected pedigree. So, this is termed a dominant trait.

Breast cancer can be a pseudodominant trait. An individual who inherits one mutated allele of the $B R C A 1$ or $B R C A 2$ gene (a partial loss-of-function or null allele) and one wild type allele may have as little as $50 \%$ of the function of the gene in most cells. But, when the wild type allele of the gene is mutated in a few breast epithelial cells due to spontaneous errors in gene copying, gene function is reduced sufficiently that those cells may become cancerous. As a result, having a mutated copy of the gene predisposes the individual toward cancer. ${ }^{11}$ In such cases, carrying one mutated allele predisposes toward occurrence of the disease, but the second allele must be mutated for disease to

9 J. Zielenski and L.C. Tsui, "Cystic fibrosis: genotypic and phenotypic variations," Annual Review of Genetics 29 (1995), 777-807.

10 B.C. Levin, K.L. Richie, and J.P. Jakupciak, "Advances in Huntington's disease diagnostics: development of a standard reference material," Expert Reviews in Molecular Diagnostics 6:4 (July 2006), 587-96.

11 D. Meaney-Delman and C.A. Bellcross, "Hereditary breast/ovarian cancer syndrome: a primer for obstetricians/gynecologists," Obstetrics and Gynecology Clinics of North America 40:3 (September 2013), 475-512. 
occur. Because such traits tend to occur in every generation within an affected pedigree, but both copies of the gene must be altered for the trait to occur, this is termed a pseudodominant trait.

While various genotypes can predispose us toward various diseases, the severity (i.e., expressivity) or the frequency of occurrence (i.e., penetrance) of a given disease can often vary among individuals who carry the same or similar disease-predisposing genotypes. This may be due to the presence of genetic variation in addition to the mutational variation that alters a disease-predisposing gene, or to other factors we will discuss below.

Variable severity of a trait among individuals genetically predisposed toward that trait is termed variable expressivity. One of the most widely observed occurrences of variable expressivity is the variation associated with the trisomy 2I, formerly termed Down's Syndrome. Individuals who possess three copies of chromosome 2I can experience a variety of effects including low muscle tone, congenital heart defects, childhood leukemia, and dementia. ${ }^{12}$ However, empirical observation reveals that different individuals with this genotype vary greatly in the severity of effects they experience. ${ }^{13}$ Thus, trisomy $2 \mathrm{I}$ is a well-recognized instance of a genotype and trait that exhibits variable expressivity.

Variable occurrence of a trait among individuals genetically predisposed toward that trait is termed variable penetrance. Women with one mutated and one wild type copy of the $B R C A 1$ gene have a nearly $60 \%$ lifetime risk of breast cancer and a $40 \%$ risk of ovarian cancer. ${ }^{14}$ The fact that these risks are not I००\% means that the association of cancer occurrence with $B R C A 1$ mutations exhibits incomplete penetrance. Thus, $B R C A 1$-dependent predisposition toward cancer is a well-recognized instance of variable penetrance.

These observations reflect the inherent complexity of human genetics and the varied relationships between human genetics and human disability and disease. The import of this variability is that, while possessing a given genotype may predispose us toward a given condition or disease, the likelihood that we will experience that disease-or the severity with which we will experience the disease, if we do-can vary greatly. Despite this inherent uncertainty, increasing availability to genetic information has motivated new approaches to decision-making regarding reproduction, lifestyle, health monitoring, and therapies, based in the belief that our genotypes determine, rather than influence, our health and well-being.

\section{Genotype-driven Decision-making}

Once the complete sequence of a "reference" human genome became available, two sets of innovations in the study of human genetics were enabled. The availability of a reference

12 M.E. Weijerman and J.P. de Winter, "Clinical Practice. The care of children with Down syndrome," European Journal of Pediatrics 169:12 (December 2010), 1445-52.

13 A. Letourneau and S.E. Antonarakis, "Genomic determinants in the phenotypic variability of Down syndrome," Progress in Brain Research 197 (2012), 15-28.

14 S. Chen and G. Parmigiani, "Meta-analysis of BRCA1 and BRCA2 penetrance," Journal of Clinical Oncology 25:11 (April 10, 2007), 1329-33. 


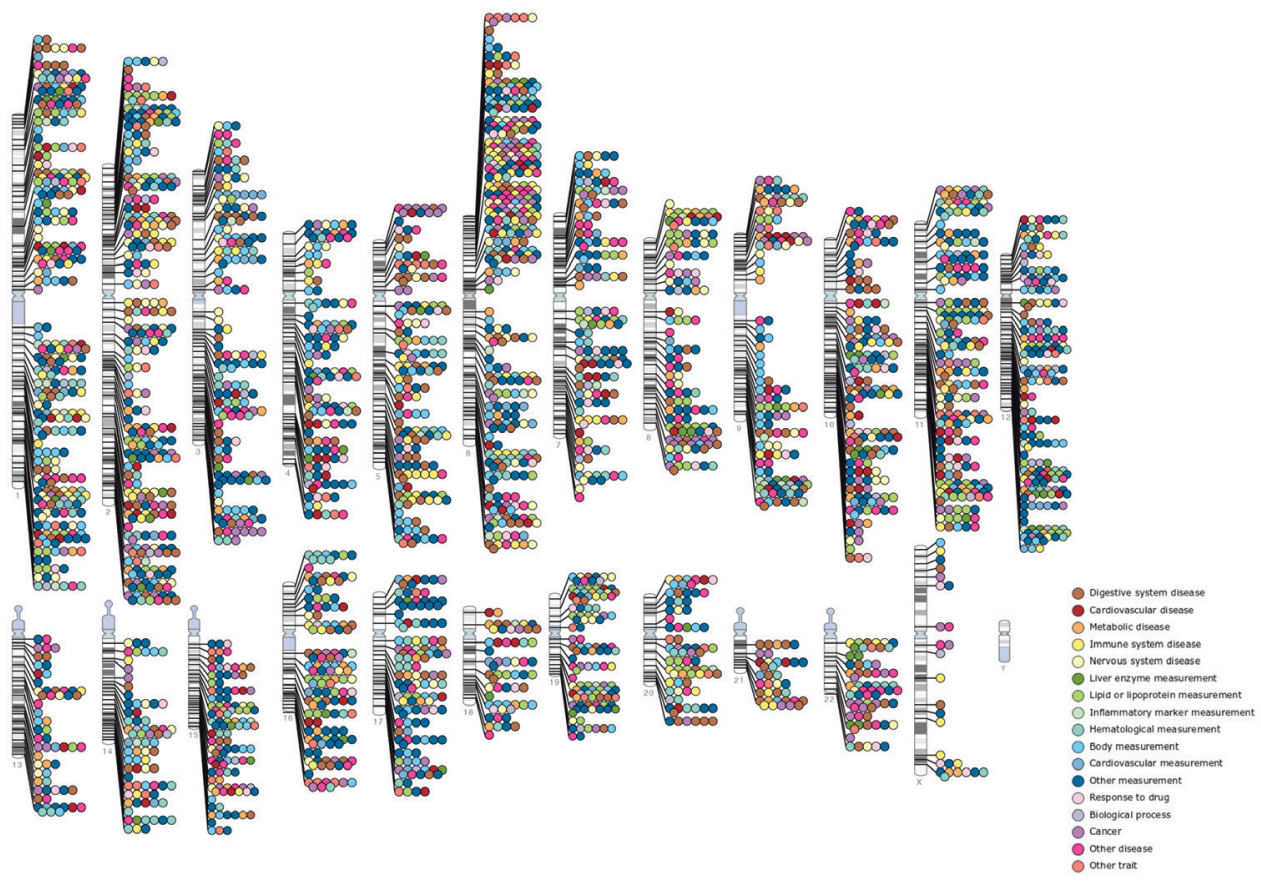

Figure 1. Compilation of results from human genome-wide association studies, as of December 2012, from the National Human Genome Research Institute of the National Institutes of Health.

sequence enabled mapping of genomic DNA sequence variation in thousands of people, which led to the accumulation of an aggregated single nucleotide polymorphism (SNP) database. This database now catalogs over 50 million single nucleotide polymorphisms (single base pair sequence variants, or SNPs) throughout the human genome. The availability of these SNPs, in turn, enabled increasingly powerful mapping of genetic variation associated with different conditions and diseases through genome-wide association studies (GWAS). As of April 20I4, over I800 GWAS have mapped sequence variation associated with nearly 700 human conditions and diseases (Figure I). ${ }^{15}$

These findings have provided many insights into numerous genetic and molecular mechanisms that underlie health and disease, and they have enabled the association of specific human genomic DNA sequence variation with particular conditions and diseases. This has enabled the use of genome-wide DNA sequencing of individuals, ${ }^{16}$ and other human genotyping technologies, ${ }^{17}$ to define genomic DNA sequence variation in

15 See "A Catalog of Published Genome-Wide Association Studies" at the National Human Genome Research Institute, http://www.genome.gov/gwastudies/.

16 D. B. Goldstein, A. Allen, J. Keebler, E.H. Margulies, S. Petrou, S. Petrovski, and S. Sunyaey, "Sequencing studies in human genetics: design and interpretation," Nature Reviews Genetics 14:7 (July 2013), 46070.

17 S. Le Scouarnec and S.M. Gribble, "Characterising chromosome rearrangements: recent technical advances in molecular cytogenetics," Heredity (Edinb) 108:1 (Jan 2012), 75-85. 


\begin{tabular}{|c|c|c|c|}
\hline Trait or Disease & $\begin{array}{l}h^{2} \text { Pedigree } \\
\text { Studies }\end{array}$ & $\begin{array}{l}h^{2} \text { GWAS } \\
\text { Hits }^{\mathrm{a}}\end{array}$ & $\begin{array}{l}h^{2} \text { All } \\
\text { GWAS SNPs }\end{array}$ \\
\hline Type 1 diabetes & $0.9^{98}$ & $0.6^{99, \mathrm{c}}$ & $0.3^{12}$ \\
\hline Type 2 diabetes & $0.3-0.6^{100}$ & $0.05-0.10^{34}$ & \\
\hline Obesity (BMI) & $0.4-0.6^{101,102}$ & $0.01-0.02^{36}$ & $0.2^{14}$ \\
\hline Crohn's disease & $0.6-0.8^{103}$ & $0.1^{11}$ & $0.4^{12}$ \\
\hline Ulcerative colitis & $0.5^{103}$ & $0.05^{12}$ & \\
\hline Multiple sclerosis & $0.3-0.8^{104}$ & $0.1^{45}$ & \\
\hline Ankylosing spondylitis & $>0.90^{105}$ & $0.2^{106}$ & \\
\hline Rheumatoid arthritis & $0.6^{107}$ & & \\
\hline Schizophrenia & $0.7-0.8^{108}$ & $0.01^{79}$ & $0.3^{109}$ \\
\hline Bipolar disorder & $0.6-0.7^{108}$ & $0.02^{79}$ & $0.4^{12}$ \\
\hline Breast cancer & $0.3^{110}$ & $0.08^{111}$ & \\
\hline Von Willebrand factor & $0.66-0.75^{112,113}$ & $0.13^{114}$ & $0.25^{14}$ \\
\hline Height & $0.8^{115,116}$ & $0.1^{13}$ & $0.5^{13,14}$ \\
\hline Bone mineral density & $0.6-0.8^{117}$ & $0.05^{118}$ & \\
\hline QT interval & $0.37-0.60^{119,120}$ & $0.07^{121}$ & $0.2^{14}$ \\
\hline HDL cholesterol & $0.5^{122}$ & $0.1^{57}$ & \\
\hline Platelet count & $0.8^{123}$ & $0.05-0.1^{58}$ & \\
\hline
\end{tabular}

Table 1. Heritable genetic variation (h2) mapped by GWAS ${ }^{18}$

individuals, and then define predispositions toward a variety of conditions and diseases. This has also led to the creation of an increasing number of custom genotyping services and companies. ${ }^{19}$ For a fee, these entities will determine the sequences of selected genes or assess genome-wide sequence variation in individuals. The challenge then becomes how one interprets this information.

This challenge is all the more acute because of another general finding from GWAS to date. The proportion of phenotypic variation that can be attributed to mappable genomic DNA sequence variation varies from 10-50\% for various diseases studied to date (Table I). This implies that 50-90\% of phenotypic variation is due to other causes, including genetic variation that has not yet been mapped, leading to the concept of the "missing heritability" for human diseases. These findings speak again to the complexity of relationships between genotype and phenotype, and imply that factors in addition to genomic variation affect the impacts of genotypes on our health and well-being. Some of this variability in phenotypic outcomes is likely attributable to additional genetic

18 Peter M. Visscher, Matthew A. Brown, Mark I. McCarthy, and Jian Yang, "Five years of GWAS discovery," in The American Journal of Human Genetics 90 (January 13, 2012), 12.

19 J.S. Roberts and J. Ostergren, "Direct-to-consumer genetic testing and personal genomics services: a review of recent empirical studies," Current Genetic Medicine Reports 1:3 (September 2013), 182-200. 
or epigenetic variation and other factors, as discussed below. In this sense, "diseasecausing genetic variation" can be more accurately described as "disease-predisposing genetic variation." In light of these findings, the fact that genotypic variation possesses incomplete power to explain the incidence and severity of many diseases implies we must be even more thoughtful and cautious in interpreting the likely impacts of genomic variation on health outcomes. Still, having acknowledged these findings, there is no doubt that access to genotypic information is playing an increasing role in reproductive choice as well as prophylactic and therapeutic treatment choices.

There is no doubt that access to genotypic information is playing an increasing role in reproductive choice as well as prophylactic and therapeutic treatment choices.

Reproductive choices are being guided increasingly by access to information regarding the genotypes of prospective parents, the genotypes of embryos created by in vitro fertilization, ${ }^{20}$ and the genotypes of fetuses in utero ${ }^{21}$ at increasingly earlier times after conception. Genotyping of prospective parents allows many couples to determine whether they possess genotypes that, if transmitted to their children, would predispose those children to challenging or life-threatening genetic conditions. Some of these couples will choose to refrain from conceiving. Others may decide to conceive by conventional means or by in vitro fertilization, and then choose which embryos to implant or which pregnancies to continue based on genotypic information about themselves, the embryos they create, or the fetuses they carry. Some couples may make such choices because they believe the genetic information they possess will allow them to determine whether they will bring into existence a child who will suffer a short and difficult life, a child who will experience insurmountable or recurrent challenges throughout life, or a child who will suffer a debilitating condition that may shorten or portend a difficult end to her life. And, in many cases this belief would be realized in the life of a child born into the world because, for some traits with genetic underpinnings, the predictions of disability, suffering, or premature death can be made with a substantial degree of certainty. However, the confidence with which such genetic determinism is invoked should be considered carefully, in many cases, in light of the variability in expressivity and penetrance known to be associated with many human traits and diseases.

20 N. Van der Aa, M. Zamani Esteki, J.R. Vermeesch, and T. Voet, "Preimplantation genetic diagnosis guided by single-cell genomics," Genome Medicine 5:8 (August 19, 2013), 71.

21 A. Hall, A. Bostanci, and C.F. Wright, "Non-invasive prenatal diagnosis using cell-free fetal DNA technology: applications and implications," Public Health Genomics 13:4 (2010), 246-55. 
We may stand on firmer ground when we consider the use of genetic information to guide the implementation of specific therapeutic treatments or prophylactic interventions for fetuses, children, and adults, in the realm known as personalized medicine. ${ }^{22}$ One arm of personalized medicine has employed the acquisition of genotypic information for patients with specific cancers, or with inherited predispositions toward certain cancers, as the basis for defining therapeutic or prophylactic interventions most likely to drive cancer into remission or prevent its occurrence. Women diagnosed with breast cancer who carry an increase in the copy number for the HER2 gene, a cell signal receptor that stimulates cell division, often experience remission when treated with Trastuzumab, ${ }^{23}$ an antibody that inhibits the receptor from signaling. People with chronic myeloid leukemia who carry a gene rearrangement that abnormally fuses portions of the BCR and ABL proteins, and creates another unregulated signal that stimulates cell division, can experience remission when treated with imatinib, nilotinib, or dasatinib, ${ }^{24}$ small molecules that inhibit the novel BCR:ABL fusion protein. People being treated with warfarin as an anticoagulant therapy are now routinely genotyped for the warfarin-inactivating Cytochrome $\mathrm{P}_{45} 0$ gene $\mathrm{CYP}_{2} \mathrm{C}_{9}$. This enables adjustment of warfarin dosing levels so that the extent of inhibition of clot formation is effective and safe based on the genetically inferred ability of the patient to metabolize warfarin. ${ }^{25}$ In these instances, when relationships between genotypes and outcomes are well-defined, genetic determinism can be invoked with substantial confidence.

But even in this realm, the variability of relationships between genotypes and phenotypes can come into play. Some women who carry $B R C A 1$ or $B R C A 2$ mutations will decide, after careful deliberation, to pursue complete mastectomies and ovarectomies to substantially reduce or eliminate the possibility that they will experience breast or ovarian cancer. ${ }^{26}$ Some men with these genotypes will decide to undergo complete mastectomies as well. These deliberations are in most if not all cases, undertaken with the knowledge of overall trends of up to $60 \%$ penetrance for breast cancer and up to

22 L. Hood and M. Flores, "A personal view on systems medicine and the emergence of proactive $\mathrm{P}_{4}$ medicine: predictive, preventive, personalized and participatory," New Biotechnology 29:6 (September 15, 2012), 613-24.

23 M.C. Figueroa-Magalhães, D. Jelovac, R.M. Connolly, and A.C. Wolff, "Treatment of HER2-positive breast cancer," Breast 23:2 (April 2014), 128-36.

24 E. Jabbour and J.H. Lipton, "A critical review of trials of first-line BCR-ABL inhibitor treatment in patients with newly diagnosed chronic myeloid leukemia in chronic phase," Clinical Lymphoma, Myeloma Q Leukemia 13:6 (December 2013), 646-56.

25 M. Franchini, C. Mengoli, M. Cruciani, C. Bonfanti, and P.M. Mannucci, "Effects on bleeding complications of pharmacogenetic testing for initial dosing of vitamin $\mathrm{K}$ antagonists: a systematic review and meta-analysis," Journal of Thrombosis and Haemostasis 2014 Jul 8. doi: 10.111/jth.12647. [Epub ahead of print]

26 A. Stuckey, D. Dizon, J. Scalia Wilbur, J. Kent, T. Tejada-Berges, J. Gass, and R. Legare, "Clinical characteristics and choices regarding risk-reducing surgery in BRCA mutation carriers," Gynecologic and Obstetric Investigation 69:4 (June 2010), 270-3. 
$40 \%$ penetrance for ovarian cancer among carriers of $B R C A 1$ or $B R C A 2$ mutations. ${ }^{27}$ Still, both choices constitute irrevocable prophylactic therapies that can be life-altering, and may have been unnecessary had the unforeseeable impacts of variable penetrance favored the decision-maker.

\section{Complex Genetic Variation and Epigenetic Variation Affect the Impacts of Genotypes}

The reliance on genotypic information for making the health-related choices outlined above, and for many other genotype-driven choices, is based on the confidence with which genotypes can be determined and their impacts can be predicted. While the former is quite high, given appropriate technical expertise, the latter is less so and can be influenced by a number of genetic, biological, and environmental variables. In fact, the outcomes mediated by genotypes that predispose us toward disease can be influenced by additional genetic variation we possess that affects other genes that interact with a disease-predisposing gene (modifying mutations), or by the impacts of epigenetic variation on the function of the disease-predisposing gene or the integrative network within which that gene acts to mediate cellular functions. These types of influences can affect the impacts of genetic variation that underlie recessive, dominant, and pseudodominant traits.

The presence of mutations in addition to those that affect a gene associated with a specific disease-i.e., modifying mutations_can increase or lessen the severity of the disease impacts associated with the particular disease-predisposing genotype. One of the best understood of these instances is the relationship between accrual of increasing numbers of modifying oncogenic (cancer-associated) mutations and the severity of colon cancer. The APC gene is a recessive gene, the loss of which predisposes intestinal cells toward cancerous growth. In elegant genetic studies, researchers have shown that as particular additional modifying mutations accrue in intestinal cells, those cells display increasingly misregulated growth. ${ }^{28}$ While mutations in the APC gene can predispose us toward cancer, the severity of the disease will depend critically on the accumulation of additional mutations we receive from our parents or that arise by errors in gene copying during the normal replacement of intestinal cells. Thus, the severity of-and risk from-cancer in an individual who carries two mutated copies of the APC gene will depend importantly on additional mutations she inherits or acquires during her life. In a converse sense, individuals with genotypes that predispose them toward Type 2 diabetes, such as HNF4alpha or WFS1 loss-of-function mutations, can benefit from the

27 D. Meaney-Delman and C.A. Belcross, "Hereditary breast/ovarian cancer syndrome: a primer for obstetricians/gynecologists," Obstetrics and Gynecology Clinics of North America 40:3 (September 2013), 475-512.

28 S. Jones, W.D. Chen, G. Parmigiani, F. Diehl, N. Beerenwinkel, T. Antal, A. Traulsen, M.A. Nowak, C. Siegel, V.E. Velculescu, K.W. Kinzler, B. Vogelstein, J. Willis, and S.D. Markowitz, "Comparative lesion sequencing provides insights into tumor evolution," Proceedings of the National Academy of Sciences of the United States of America 105:11 (March 18, 2008), 4283-8. 
presence of loss-of-function mutations in the $S L C_{30} A 8$ gene, which reduce the incidence of diabetes. ${ }^{29}$ People with genotypes that predispose them toward atherosclerotic heart disease, such as LDLR loss-of-function mutations, can benefit from the presence of lossof-function mutations in the PCSKg gene, ${ }^{30}$ which lower levels of circulating cholesterol. The logical extension of these findings implies that the probable impact of a single genotype that predisposes us toward a particular disease can be influenced critically by variation in other genes for which we may not know we carry mutations. This again speaks to the care required in interpreting the likely impacts of disease-predisposing mutations we discover through targeted genetic analysis or attempted genome-wide analysis, given that we may fail to discover other exacerbating or beneficial genetic variation that we possess.

Another type of variation that can dramatically, or subtly, influence the impacts of disease-predisposing genotypes is epigenetic variation. Epigenetics ("over-" or "upon-" genetics) encompasses the mechanisms by which cells regulate the function of a gene without altering the DNA sequence of the gene. And, as we will discuss, epigenetic mechanisms that may modulate the impacts of disease-predisposing genotypes can be influenced by life history and experience, and epigenetic states themselves may be inherited between generations.

Two of the three primary epigenetic mechanisms we know to exist affect the likelihood that the DNA constituting a gene will be copied into a messenger RNA (mRNA) by molecular machines that "transcribe" the genetic code in DNA into a "translatable" RNA code (mRNA) that is a molecular substrate for protein synthesis. These mechanisms exert their effects by compacting or unwinding our genomic DNA, ${ }^{31}$ which must be tightly wound around specialized proteins to fit into the microscopic nucleus of each of our cells. These mechanisms are critical because our genome, which is two meters long, must fit into a cell nucleus that is only two millionths of a meter across. This is possible because DNA is wound tightly around sets of proteins called "histones" to form "beads on a string," and these strings are wound up by successive compaction until our genome fits into each nucleus. Genes can be turned on when our epigenetic machinery adds twocarbon chemical units (acetyl groups, added via "acetylation") to histones. This "opens" genes so that they can be transcribed, and are thus "activated." Conversely, genes can be turned off when our epigenetic machinery adds one-carbon units (methyl groups, added via "methylation") to our DNA or our histones, or when they remove two-carbon

29 J. Flannick et al., "Loss-of-function mutations in SLC30A8 protect against type 2 diabetes," Nature Genetics 46:4 (April 2014), 357-63.

30 D. Urban, J. Pöss, M. Böhm, and U. Laufs, "Targeting the proprotein convertase subtilisin/kexin type 9 for the treatment of dyslipidemia and atherosclerosis," Journal of the American College of Cardiology 62:16 (October 15, 2013), 1401-8.

31 G. Kelsey and R. Feil, "New insights into establishment and maintenance of DNA methylation imprints in mammals," Philosophical Transactions of the Royal Society of London. Series B, Biological Sciences 368:1609 (January 5, 2013): 20110336. See also T. Kourzarides, "Chromatin modifications and their function," Cell 128:4 (February 23, 2007), 693-705. 
acetyl groups from histones, compacting genes so that they cannot be transcribed, and are thus "repressed."

Epigenetic states that vary during the course of our lives, and affect somatic cells in our bodies (i.e., the cells in our bodies other than those that give rise to gametes),,$^{32}$ can further modulate the impacts of disease-predisposing genotypes on our health. Genetic investigations over the past 70 years have revealed that epigenetic states that affect our germ line cells, which give rise to gametes (i.e., eggs and sperm), can also be transmitted through multiple generations-so that epigenetic variation can be inherited, in a manner analogous to the inheritance of genetic variation. ${ }^{33}$ As a result, the influences of life history and experience (and the effects of some of the "sins" and misfortunes of the father or the mother) can be passed down from generation to generation.

\section{The influences of life history and experience (and the effects of some of the "sins" and misfortunes of the father or the mother) can be passed down from generation to generation.}

In the general sense, epigenetic states that affect somatic cells or germ line cells lead to the activation or repression of individual genes, or sets of genes, with attendant advantageous or disadvantageous effects. Normal patterns of gene activation and repression are essential for normal cell function. These patterns are diverse and can vary by cell type. But, the aberrant epigenetic repression of a gene required for the function of a cell will impede development or homeostasis of that cell and the tissue in which it resides, and may cause disease in a manner analogous to a loss-of-function mutation in that same gene, e.g., loss of response to insulin underlying some forms of diabetes. Similarly, aberrant epigenetic activation of a gene may lead to expression of a gene product that will cause cells to be misregulated in a manner analogous to a gainof-function mutation in that same gene, e.g., overexpression of cellular growth factors underlying some forms of cancer.

These and other mechanisms of complex genetic variation and epigenetic variation can affect the impacts on our health of genotypes that predispose us toward different conditions and diseases. Indeed, the health outcomes associated with the presence of disease-predisposing mutations in ourselves, our children, and our neighbors can also be influenced by the effects of our environment and life history on genetic and

32 R.L. Jirtle and M.K. Skinner, "Environmental epigenomics and disease susceptibility," Nature Reviews Genetics 8:4 (April 2007), 253-62.

33 M.K. Skinner, M. Manikkam, and C. Guerrero-Bosagna, "Epigenetic transgenerational actions of environmental factors in disease etiology," Trends in Endocrinology and Metabolism 21:4 (April 2010), 214-22. 
epigenetic inheritance, as well as by the effects of mind-body interactions framed, within one school of thought by the concepts of psychoneuroimmunology. ${ }^{34}$

\section{Environment and Perception Affect the Impacts of Genotypes}

Exposure to deleterious environmental conditions, including chemicals ${ }^{35}$ and radiation ${ }^{36}$ in our environments, can increase the rate at which erroneous gene copying introduces mutations into our genes as well as the rate at which mistakes during the repair of damage to our DNA introduces mutations in our germ line cells ${ }^{37}$ and our somatic cells. ${ }^{38}$ The former mutations (in germ line cells) can be transmitted to our children, and the latter (in somatic cells) can affect our health, for good or ill. Exposure to compounds and conditions that increase the rates of mutation in our germ line cells, i.e., mutagens, occur by many routes. Carcinogenic compounds may arise in, or be mistakenly incorporated into, processed or cooked foods. We can take up harmful chemicals from our environment by contact, ingestion, or inhalation. Voluntary mutagenesis by the use of tanning beds, or frolicking in the sun without adequate protection, increases the rate of mutation in our epidermis. Involuntary exposure to nuclear radiation, as occurred during the atomic bombing of Japan (I945) or the nuclear plant disaster at Chernobyl (I986), also increases mutation rates. In each of these situations, intentional or unbidden interactions with our environments can increase the rate at which we accumulate mutations. The resulting "genetic load" in our germ line cells and our somatic cells can affect the outcomes of disease-predisposing mutations we already carry or that we pass on to our children. The many and varied impacts of genetic complexity-including the interactions of a number of mutations to cause, exacerbate, or ameliorate particular diseases with genetic underpinnings — can affect health outcomes, as outlined above.

Various lines of evidence have revealed that epigenetic variation that arises due to certain circumstances of our life histories can affect the impacts of disease-predisposing mutations on health outcomes, ${ }^{39}$ and can itself be inherited and affect health outcomes in generations descending from individuals with particular life histories. ${ }^{40}$ Maternal levels

34 E.M. Sternberg and P.W. Gold, "The mind-body interaction in disease," Scientific American, Special Edition: The Hidden Mind, vol. 12 (2002): 82-29. See also Q. Yan, "The role of psychoneuroimmunology in personalized and systems medicine," Methods in Molecular Biology 934 (2012), 3-19.

35 T.M. Singer and C.L. Yauk, "Germ cell mutagens: risk assessment challenges in the 21st century," Environmental and Molecular Mutagenesis 51:8-9 (October-December 2010), 919-28.

36 K. Suzuki and S. Yamashita, "Low-dose radiation exposure and carcinogenesis," Japanese Journal of Clinical Oncology 42:7 (July 2012), 563-8.

37 T.M. Singer and C.L. Yauk, "Germ cell mutagens: risk assessment challenges in the 21st century," Environmental and Molecular Mutagenesis 51:8-9 (October-December 2010), 919-28.

38 L.A. Forsberg, D. Absher, and J.P. Dumanski, "Non-heritable genetics of human disease: spotlight on post-zygotic genetic variation acquired during lifetime," Journal of Medical Genetics 50:1 (January 2013), 1-10.

39 M.K. Skinner, M. Manikkam, and C. Guerrero-Bosagna, "Epigenetic transgenerational actions of environmental factors in disease etiology," Trends in Endocrinology and Metabolism 21:4 (April 2010), 214-22.

40 R.L. Jirtle and M.K. Skinner, "Environmental epigenomics and disease susceptibility," Nature Reviews 
of folic acid - a chemical resource for the epigenetic methylation of DNA and histonesduring pregnancy can affect the frequency and intensity of fetal growth defects, ${ }^{41}$ including neural tube defects such as spina bifida, by affecting the development of fetal cells and tissues. In a variety of cancers, the DNA of genes that stimulate cell growth may be undermethylated ("hypomethylated") and therefore more active while the DNA of genes that inhibit cell growth may be overmethylated ("hypermethylated") and therefore less active. Effects of both types enable aberrant cell growth, i.e., stimulators of growth that are more active or inhibitors of growth that are less active. ${ }^{42}$ A number of developmental dysregulation syndromes catalogued in humans (e.g., prenatal overgrowth, or low birth weight) have been shown to exhibit increased incidence in children conceived by in vitro fertilization, ${ }^{43}$ and are correlated with changes in epigenetic imprinting mediated by DNA methylation in eggs and sperm. ${ }^{44}$ Children of mothers who suffered starvation during the I944 Hongerwinter in the Netherlands exhibited low birth weight, increased obesity, and heart disease, ${ }^{45}$ implying starvation-induced epigenetic variation modulating fetal growth may have been passed from mothers to children. Some overweight fathers have been found to pass on in their sperm copies of the IGF2 growth factor gene with patterns of genomic DNA methylation that differ from those in males who are not obese. ${ }^{46}$ In mice, which are amenable to directed genetic analysis and reproduce rapidly, epigenetic variation occurring in ancestors has been found to be transmitted for as many as five generations that succeed parents in which epigenetic variation first occurs. ${ }^{47}$ These and

Genetics 8:4 (April 2007), 253-62.

41 E.H. Reynolds, "The neurology of folic acid deficiency," Handbook of Clinical Neurology 120 (2014), 927-43.

42 J. Sandoval and M. Esteller, "Cancer epigenomics: beyond genomics," Current Opinion in Genetics and Development 22:1 (February 2012), 50-55.

43 G. Lazaraviciute, M. Kauser, S. Bhattacharya, P. Haggarty, and S. Bhattacharya, "A systematic review and meta-analysis of DNA methylation levels and imprinting disorders in children conceived by IVF/ ICSI compared with children conceived spontaneously," Human Reproduction Update (June 24, 2014), pii: dmuo33.

44 M.K. Skinner, M. Manikkam, and C. Guerrero-Bosagna, "Epigenetic transgenerational actions of environmental factors in disease etiology," Trends in Endocrinology and Metabolism 21:4 (April 2010), 214-22.

45 G.P. Ravelli, Z.A. Stein, and M.W. Susser, "Obesity in young men after famine exposure in utero and early infancy," New England Journal of Medicine 295:7 (August 1976): 349-53. See also R.C. Painter, T.J. Roseboom, and O.P. Bleker, "Prenatal exposure to the Dutch famine and disease in later life: an overview," Reproductive Toxicology 20:3 (September-October 2005), 345-52.

46 A. Soubry, J.M. Schildkraut, A. Murtha, F. Wang, Z. Huang, A. Bernal, J. Kurtzberg, F.L. Jirtle, S.K. Murphy, and C. Hoyo, "Paternal obesity is associated with IGF2 hypomethylation in newborns: results from a Newborn Epigenetics Study (NEST) cohort," BMC Medicine 11 (February 6, 2013), 29.

47 M. Rassoulzadegan, V. Grandjean, P. Gounon, S. Vincent, I. Gillot, and F. Cuzin, "RNA-mediated non-mendelian inheritance of an epigenetic change in the mouse," Nature 441:7092 (May 25, 2006), 469-74. See also K.D. Wagner, N. Wagner, H. Ghanbarian, V. Grandjean, P. Gounon, F. Cuzin, and M. Rassoulzadegan, "RNA induction and inheritance of epigenetic cardiac hypertrophy in the mouse," Developmental Cell 14:6 (June 2008), 962-9. 
other analogous findings imply that epigenetic variation not only affects the outcomes of somatic cell development but that it can also be transmitted via germ line cells and thereby constitute intergenerationally heritable epigenetic variation. Such epigenetic variation can, in turn, affect the health outcomes that result from disease-predisposing genotypes, as outlined above.

\section{INTERACTION OF THE BRAIN AND IMMUNE SYSTEM}

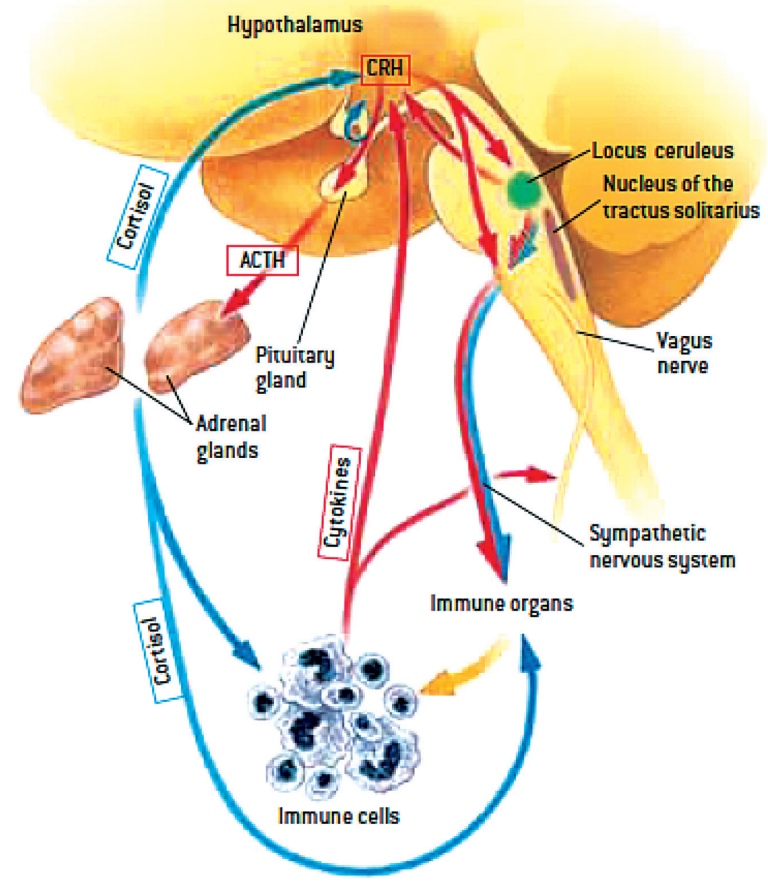

Figure 2. Pathways by which the brain and immune system stimulate (red arrows) or inhibit (blue arrows) each other. ${ }^{48}$

In an effort to extend our grasp of the mechanisms that may underlie modulation of the health outcomes associated with simple genetic and epigenetic variation, increasing attention is being devoted to the functions of a systems-level frameworktermed psychoneuroimmunology — that may explain facets of the modulation of health and wellness through mind-body interactions. This framework offers the possibility that health outcomes associated with disease-predisposing genotypes may be modulated by integrative interactions among our central nervous system, our neuroendocrine system, and our immune system (Figure 2).

One perspective within this framework is the growing realization that many disease states are exacerbated by inflammatory activities of the immune system, and 
that inflammation is mediated by the interplay among our central nervous system, neuroendocrine system, and immune system. ${ }^{49}$ Aberrant inflammatory function has been implicated in Alzheimer's disease, multiple sclerosis, cardiovascular disease, Type 2 diabetes, rheumatoid arthritis, psoriasis, and some forms of cancer. ${ }^{50}$ Our immune system cells have access to our entire interior cellscape. This immune cell-mediated surveillance functions to maintain and may enhance wellness, but hyperactivation of the immune system can lead to, or exacerbate, a variety of conditions and diseases associated with genetic and epigenetic variation. The known connectivity among the brain, the sympathetic and parasympathetic nervous systems, and the lymphoid organs ${ }^{51}$ enables us to entertain the possibility that our perception of stress and our sense of wellbeing may modulate immune system-mediated self-surveillance and inflammation, and thereby modulate the health outcomes for conditions and diseases associated with genetic and epigenetic variation. Furthermore, our growing understanding of mind-body interactions allows us to entertain the possibility that our psychological state-of-mind may modulate the integration of our central nervous system, neuroendocrine system, and immune system in ways that can benefit or degrade our overall health and sense of well-being within the biological framework of the genetic and epigenetic variation that we inherit and accrue throughout our lives. Given the intricate interrelationships in the life of the human mind and body that appear to unfold among these systems, might grace-or existence within a "state of grace"-have the power to affect the impacts of genetic and epigenetic variation on our health and well-being?

\section{Our perception of stress and our sense of well-being may modulate the health outcomes for conditions and diseases associated with genetic and epigenetic variation.}

\section{Might Grace Affect the Impacts of Genetic and Epigenetic Variation on Our Lives?}

The preceding sections have attempted to explain and explore the bases for the genesis of genetic determinism during the past century, and facets of its relationship to the prediction of our health outcomes and biological destinies. The subsequent consideration of some of the complexities of our biology and of our interactions with the environment

49 J.K. Kiecolt-Glaser, L. McGuire, T.F. Robles, and R. Glaser, "Psychoneuroimmunology: psychological influences on immune function and health," Journal of Consulting and Clinical Psychology 70:3 (June 2002), 537-47.

50 J.K. Kiecolt-Glaser, L. McGuire, T.F. Robles, and R. Glaser, "Emotions, morbidity, and mortality: new perspectives from psychoneuroimmunology," Annual Review of Psychology 53 (2002), 83-107.

51 E.M. Sternberg and P.W. Gold, "The mind-body interaction in disease," Scientific American, Special Edition: The Hidden Mind, vol. 12 (2002), 82-29. See also A. Gadek-Michalska and J. Bugajski, "Interleukin-1 (IL-1) in stress-induced activation of limbic-hypothalamic-pituitary adrenal axis," Pharmacological Reports 62:6 (November-December 2010), 969-82. 
implies that, while genetic variation predisposing us toward certain conditions or diseases can affect our health, our lives, and the choices we make for ourselves and for others, the impacts of genetic variation associated with specific conditions or diseases can be influenced substantially by additional genetic variation, by epigenetic variation, and by mind-body interactions. In this last section, we will consider whether the gift of grace or dwelling in a "state of grace" might influence the impacts of genetic and epigenetic variation on our health and our biological destinies.

Within the context of Christian theology, grace is a gift granted to us freely, without regard to merit, by a loving God. The word is derived from the Latin gratia, which was used by second century Roman translators of the New Testament for the Greek charis-a gift or blessing. Believers seek grace, cherishing the precious gift we regard as a reflection of God's love for us. We ask for the grace to bear our burdens in times of trouble, and the grace to find humility in times of success. We may believe that the health, well-being, and good fortune we experience are the gracious gifts of a loving God. When confronted with illness or the prospect of illness, affecting us or those we love, we often ask for the gift of God's protective, healing grace. So, might grace ameliorate the potential impacts on our biological destinies of disease-predisposing genetic and epigenetic variation, or forestall the impacts of such variation?

Miraculous healings, believed to result from the agency of God's supernatural grace, are described in the Old and New Testaments. They continue to be reported to the present day, and in some instances investigated and affirmed by the Congregation for the Causes of Saints within the Roman Catholic Church. Whether these events occur through the supernatural agency of God's grace can never be proven. Similarly, we can never know whether such grace reduces the severity of disease when it does occur, or forestalls the occurrence of disease when it might occur. The belief in such causality must remain a matter of faith. But, it may be that coming to dwell within a "state of grace" could affect mind-body interactions (e.g., as outlined, in part, by psychoneuroimmunology) in ways that prevent or reverse disease, or reduce its severity, despite the fact that our genetic or epigenetic constitution predisposes us toward ill health.

We might consider that we could dwell within a "state of grace" for any of a number of reasons. We might believe ourselves to be the beneficiaries of the grace of a loving God, to have the support of loving family and friends, to be privy to a transcendent reality, to understand essential deep truths, to be one with the universe, to be at peace, to be living in mindfulness, to have achieved detachment. Why would arriving in such "places" improve our wellness, even in the face of predispositions toward disease?

An expanding corpus of evidence reveals that interactions among our psychology, our physiology, and our bodies can powerfully shape our health and well-being-exacerbating or ameliorating (and possibly preventing) disease, or promoting its occurrence. A more technical conceptualization of these interactions is provided by the framework of psychoneuroimmunology, mentioned earlier. A more colloquial conceptualization 
is provided by the framework of "mind-body interaction," ${ }^{2}$ which encompasses the practice and evaluation of "mind-body medicine." ${ }^{53}$ Whichever framework one might prefer, it is becoming increasingly clear that normal and aberrant functioning of our complex mind-body ecosystem are critically dependent on interactions among our brain (central nervous system), our sympathetic and parasympathetic nervous systems (neuroendocrine systems that mediate action and impart stress, or mediate relaxation and reduce stress, respectively), and our immune system. Synergies and perturbations that occur among these three systems can enhance or degrade our health, and can thereby modulate the impacts of our predispositions toward disease, and our experience of disease.

Mind-body interactions are multidirectional and depend in part on a complex network of interactions among our brain, our neuroendocrine system, and our immune system. Anxiety or the perception of stress can stimulate our neuroendocrine system to increase heart rate and blood pressure, exacerbating cardiovascular disease. ${ }^{54}$ Those experiences and perceptions can stimulate the release of neuroendocrine signals that impede the functions of critical immune cells. ${ }^{55}$ In this manner, anxiety and stress can increase our susceptibility to infectious disease and may increase our susceptibility to cancer, cellular degeneration, and other diseases. They may do so by reducing the abilities of our immune system to surveil and mobilize cells to eliminate infectious agents or aberrant somatic cells that are infected, cancerous, degenerating, or otherwise damaged. Other studies imply that stress, and attendant signaling by the nervous system, can contribute to chronic hyperactivation of immune system inflammatory responses and to harmful cellular inflammation. ${ }^{56}$ An expanding medical and scientific literature supports the theory that chronic inflammation can contribute to the development and severity of diabetes, cardiovascular disease, pulmonary disease, neurological disease, and other diseases. $^{57}$

Conversely, immune system cells can release biochemical signals (e.g., "cytokines”) that modulate brain function and neuroendocrine signaling, influence our affective

52 G.D. Jacobs, "The physiology of mind-body interactions: the stress response and the relaxation response," Journal of Alternative and Complementary Medicine 7 (2001, Supplement 1), S83-S92.

53 J.A. Astin, S.L. Shapiro, D.M. Eisenberg, and K.L. Forys, "Mind-body medicine: state of the science, implications for practice," Journal of the American Board of Family Practice 16:2 (March-April 2003), 131-47.

54 R. Kvetnansky, X. Lu, and M.C. Ziegler, "Stress-triggered changes in peripheral catecholaminergic systems," Advances in Pharmacology 68 (2013), 359-97.

55 J.K. Kiecolt-Glaser, L. McGuire, T.F. Robles, and R. Glaser, "Psychoneuroimmunology: psychological influences on immune function and health," Journal of Consulting and Clinical Psychology 70:3 (June 2002), 537-47.

56 N. Rohleder, "Acute and chronic stress induced changes in sensitivity of peripheral inflammatory pathways to the signals of multiple stress systems," Psychoneuroendocrinology 37:3 (March 2012), 307-16.

57 R. Medzhitov, “Origin and physiological roles of inflammation," Nature 454:7203 (July 24, 2008), 42835 . 
states, or exacerbate neuroinflammation in the central nervous system. ${ }^{58}$ Some immune cells can cross the blood-brain barrier and harm neuronal cells within the central nervous system, initiating or aggravating neurological and mood disorders. It would be surprising, indeed, if these deleterious interactions and their synergistic modulation did not affect the impacts of our genetic and epigenetic predispositions toward disease. These and other mechanisms described — and yet to be described — underlie the abilities of our brain, neuroendocrine systems, and immune system to ameliorate and exacerbate our predispositions toward bodily dysfunction and disease.

The premise that dwelling in a state of grace could positively modulate mind-body interactions, and improve health or forestall disease, rests in part on the premise that the perception of well-being, which we would expect to experience when we dwell in a state of grace, positively modulates neurologic, circulatory, metabolic, and immune function. This premise is supported by consideration of the physiological and perceptual experiences of adherents of healthy lifestyles, religious belief, mystic practice, meditation, and mindfulness-based stress reduction. These experiences and practices have been shown to reduce stress and improve relaxation and psychological state, and they may reduce symptoms of chronic pain, fibromyalgia, cardiovascular disease, and other diseases. ${ }^{59}$

It seems likely that these benefits accrue because our central and peripheral perception modulate our mind-body ecosystem, including our immune system, central nervous system, and neuroendocrine system in ways that can divert or quell the storms of neurologic, immune, and other disease, thereby leading to improvements in our health and in our sense of well-being. And, if that is the case, as seems very likely, it's a short walk to the place from which we could posit that the perception, or the reality, of dwelling in a state of grace can ameliorate the impacts of genetic or epigenetic variation that predispose us toward disease. And in this way, dwelling in a state of grace may constitute yet another means of moderating the potency of genetic determinism in our lives.

58 M.A. Erickson, K. Dohi, and W.A. Banks, "Neuroinflammation: a common pathway in CNS diseases as mediated at the blood-brain barrier," Neuroimmunomodulation 19:2 (2012), 121-30.

N. Morgan, M.R. Irwin, M. Chung, and C. Wang, "The effects of mind-body therapies on the immune system: meta-analysis," PLoS One 9:7 (July 2, 2014), e100903. See also S.L. Keng, M.J. Smoski, and C.J. Robins, "Effects of mindfulness on psychological health: a review of empirical studies," Clinical Psychology Review 31:6 (August 2011), 1041-56. See also F. Saatcioglu, "Regulation of gene expression by yoga, meditation and related practices: a review of recent studies," Asian Journal of Psychiatry 6:1 (February 2013), 74-7. See also R.A. Abbot, R. Whear, L.R. Rodgers, A. Bethel, J. Thompson Coon, W. Kuyken, K. Stein, and C. Dickens, "Effectiveness of mindfulness-based stress reduction and mindfulness-based cognitive therapy in vascular disease: A systematic review and meta-analysis of randomised controlled trials," Journal of Psychosomatic Research 76:5 (May 2014), 341-51. See also E. Nagele, K. Jeitler, K. Horvath, T. Semlitsch, N. Posch, K.H. Herrmann, U. Grouven, T. Hermanns, L.G. Hemkens, and A. Siebenhofer, "Clinical effectiveness of stress-reduction techniques in patients with hypertension: systematic review and meta-analysis," Journal of Hypertension July 31, 2014. Epub ahead of print. See also D. Speigel, "Minding the body: psychotherapy and cancer survival," British Journal of Health Psychology 19:3 (September 2014), 465-85. 


\section{Summary points}

- Genetic determinism is a powerful, but imperfect, framework.

- Disease-predisposing genotypes affect health outcomes and biological destinies, but may not determine them in every detail.

- Impacts of disease-predisposing genotypes can be affected by genetic and epigenetic complexity and by perception.

- Impacts of disease-predisposing genotypes may be modulated when we dwell in a state of grace.

- The definition of genetic variation and its interpretation must be guided by incomplete information in almost every case due to the incompleteness of genotyping, unavoidable errors in genotyping, and our incomplete understanding of biological mechanisms.

- Given the necessarily incomplete nature of genotypic information and its interpretation, and the many variables that can affect the impacts on health of disease-predisposing genotypes, decisions guided by genotypic information should be undertaken carefully, with awareness of qualifying considerations. 